\title{
Public awareness, knowledge, and attitude toward Alzheimer's disease in Aseer region, Saudi Arabia
}

\author{
Adel Ali Alhazzani ${ }^{1 *}$ (D), Ali Mohammed Alqahtani ${ }^{2}$, Mohammed Saeed Alqahtani, ${ }^{3,4}$, \\ Tariq Mohammed Alahmari ${ }^{4}$ and Abdulmajeed Abdullah Zarbah $^{5}$
}

\begin{abstract}
Background: Alzheimer's disease (AD) is a major public health problem and represents commonest form of dementia that affects many aspects of brain functions and contributes to $60-70 \%$ of dementia cases. No study has been conducted in Saudi Arabia to measure the prevalence of AD. However, approximately there are at least 50,000 patients in Saudi Arabia based on an expert's estimation. Public knowledge and awareness about Alzheimer's disease are crucial for early diagnosis and management.

Objective: To investigate the public's knowledge and attitudes toward Alzheimer's disease in Aseer region. Subject and methods: Cross-sectional study has employed an electronic online, semi-structured, and selfadministered questionnaire, randomly distributed among participants. The questions included sociodemographics, attitudes, and knowledge panels toward Alzheimer's disease based on Alzheimer's Disease Knowledge Scale (ADKS).

Results: The study included 1374 participants with a mean age $33 \pm 11$ years (ages18-70). The majority of the participants (77\%) had no family history with Alzheimer's disease. Less than 50\% of the questions were answered correctly and the mean knowledge score was $10.77 \pm 5.11$. The results revealed that young-aged participants, females, and those having a family history of the disease, have significantly $(P<0.05)$ better AD-related knowledge.

Conclusion: The study revealed an inadequate AD-related knowledge as indicated by the low mean knowledge score. However, participants have demonstrated a positive attitude toward AD patients. More educational programs are required to enhance their awareness and knowledge about AD.
\end{abstract}

Keywords: Alzheimer's disease, Awareness, Attitude, Knowledge, Aseer, Saudi Arabia

\section{Introduction}

Alzheimer's disease (AD) is the most common neurodegenerative disease worldwide and cases are expected to increase 3-fold over the next decades [1]. The disease leads to progressive loss of neurons resulting in loss of memory, language skills, thinking, executive function, and behavioral changes where it contributes to $60-70 \%$ of cases of dementia cases. Dementia was previously

\footnotetext{
* Correspondence: aalhazzani2@ksu.edu.sa

${ }^{1}$ Department of Medicine, Neurology Unit, College of Medicine, King Saud University, Riyadh, Saudi Arabia

Full list of author information is available at the end of the article
}

studied in Saudi Arabia, where 51.9\% of the investigated patients had Alzheimer's disease, whereas vascular dementia, mixed cases, dementia with Parkinson's disease, and treatable dementia represented $18.2 \%, 15.6 \%, 7.8 \%$, and $5.2 \%$, respectively [2]. The etiologies of this lateonset form are not completely explained, but may include genetic, environmental, and lifestyle factors that influence person's risk for developing the disease [3]. The initial pathological changes affect the hippocampus, which is responsible for short and long-term memories. The degeneration of neurons is usually driven by two processes: extracellular deposition of beta amyloid-A $\beta$ 
and intracellular accumulation of tau protein resulting in neuronal loss and progressive decline in memory. Moreover, AD induces a progressive decline of other cognitive skills that involve other areas of the cerebral cortex [4]. Alzheimer's disease is distinct from normal aging; it remains the most common disease for those above 65 years old. One in nine people age 65 and older (11\%) has Alzheimer's disease, whereas about one-third of people age 85 and older (32\%) have Alzheimer's disease [5].

The disease rarely affects the younger population; younger-onset $\mathrm{AD}$ only represents $5 \%$ of all cases [6]. In Saudi Arabia, demographic data reports that only 3.2\% of the total population is above 65 years old [7]. This percent will increase in the coming years due to the rapid aging of population due to the improvement in health care programs that increases life expectancy. There are no studies about the prevalence of $A D$ in Saudi Arabia, but based on expert estimation, there might be more than 50,000 patients [8]. The prevalence is much higher in the developed countries. In the USA, there are more than 5 million people diagnosed with AD [9].

Awareness is a reflective measure of perception of a group on a given aspect of one's situation, functioning, or performance, or the resulting implications [10]. Several studies have monitored the knowledge and attitude toward Alzheimer's disease. Some studies showed that only $15.7 \%$ of participants knew the risk factors for Alzheimer's disease and $55.7 \%$ were not sure whether to share a diagnosis of Alzheimer's disease with the patient [11]. Other studies have demonstrated that people do not consider dementia as a health priority [12]. One study on different ethnic groups including Black, Hispanic, and White participants showed that all respondents more likely believed that $\mathrm{AD}$ is a normal aging complication [13].

Although this disorder is not uncommon in Saudi Arabia, the data is limited regarding the level of public awareness, and the attitudes and knowledge of dementia. To our knowledge, no study has been reported from Aseer region. This triggered our interest to investigate the public awareness, knowledge, and attitude toward Alzheimer's disease. Part of this work was presented as an abstract in American Academy of Neurology 2017 [14].

\section{Methods}

This representative cross-sectional study was conducted in Aseer region. This region is located in southern of Saudi Arabia with an area of $81,000 \mathrm{~km}^{2}$, population of $1,927,087$, and it includes six governorates [15]. The study included 1374 participants (605 males and 769 females) with a mean age $33 \pm 11$ years (range 18-70) (Table 1), and it used an online
Table 1 Demographic characteristics

\begin{tabular}{ll}
\hline Age (years) & \\
$<30$ & $586(42.6 \%)$ \\
$30-60$ & $765(55.6 \%)$ \\
$>60$ & $23(1.8 \%)$ \\
Mean \pm S.D & $32.9 \pm 10.91$ \\
Gender & \\
Male & $605(44 \%)$ \\
Female & $769(65 \%)$ \\
Social status & \\
Single & $518(37 \%)$ \\
Married & $808(58.8 \%)$ \\
Divorced & $29(2.1 \%)$ \\
Widow & $13(0.9 \%)$ \\
Separated & $6(0.4 \%)$ \\
Education level & \\
Illiterate & $2(0.1 \%)$ \\
Elementary & $28(2 \%)$ \\
Intermediate & $36(2.6 \%)$ \\
Secondary & $290(21.1 \%)$ \\
Bachelor & $906(65.9 \%)$ \\
Post-bachelor & $112(8.2 \%)$ \\
Alousing & \\
Small family & $54(3.9 \%)$ \\
Extended family & $1036(75.4 \%)$ \\
\hline & $284(20.7 \%)$ \\
\hline
\end{tabular}

electronic semi-structured self-administered questionnaire, in the Arabic language after it was translated in single forward translation step by three neurology consultants which was distributed randomly during the period from June to August 2016. The questionnaire was edited and validated with 3 neurology consultants in the regional hospital based upon their experience in clinical practice and they were guided by similar published work conducted in Riyadh City, Saudi Arabia, after obtaining the authors permission [16]. The questionnaire contained three types of questions: sociodemographic and geographic data including participant's age, sex, education level, occupation, location, marital status, and experiencing $\mathrm{AD}$ in his/ her family members; participant's attitude, his/her concerns and belief about $\mathrm{AD}$, and how he/she is dealing with AD patients (10 items); and knowledge of AD using Alzheimer's Disease Knowledge Scale (ADKS) [17]. This question panel included true and false questions about AD risk factors, assessment and diagnosis, symptoms, course, life impact, care provided, and treatment and management. 
The ethical approval for conducting this study was obtained from Head of Research Ethics Committee in King Khalid University (REC) \# 2016-08-23. The informed consent of participants was obtained prior to their participation in this study. All data were entered in Excel program, where the scale of ADKS was calculated. The data were analyzed using the SPSS software (IBM Corp. Released 2013. IBM SPSS Statistics for Windows, Version 22.0. Armonk, NY: IBM Corp.). Descriptive statistics were determined for the obtained data. The frequency distribution was calculated, and Pearson's chisquared test was used to examine the associations between categorical variables. Variables significance cutoff was at the 0.05 level.

\section{Results}

A total of 1374 participants were interviewed, most of them were Saudis (98.4\%). Their ages ranged from 18 to70 years (mean age $33 \pm 11$ years). Forty-four percent were males and $56 \%$ were females. The number of married participants was 808 (58.8\%). More than $75 \%$ were living in small families. There was wide range in the education level; however, the majority of the participants (74\%) held a bachelor degree or above. Two-third of the total number were having monthly income less than 10 , 000 Saudi Riyals. Almost, 32\% of the respondents had relatives with Dementia.

Regarding awareness toward Alzheimer's disease, almost $60 \%$ of the participants think that forgetfulness in elderly people is a part of aging process and does not need any medical consultation (Table 2 ). One-fourth reported that the patient must avoid social gatherings to avoid embarrassment. More than one-third (34.9\%) believe that $\mathrm{AD}$ is a result of evil or black magic. Only a small percentage of participants $(14.2 \%)$ would consider the traditional types of alternative medicine as a choice of treatment. The majority of participants (92.9\%) were not feeling embarrassed if one of their relatives was diagnosed with $\mathrm{AD}$. Concerning $\mathrm{AD}$ patient care, $86 \%$ preferred home care rather than nursing centers. Judiciary regulations must be considered to preserve patient rights according to $74 \%$ of the participants. There was no difference in the awareness questions among both genders and those having relative with Alzheimer's disease.

Regarding the respondent's knowledge of Alzheimer's disease, the ADKS measured the level of knowledge under the following question panels: life impact (3 items), risk factors (6 items), AD symptoms (4 items), treatment and management (4 items), assessment and diagnosis (4 items), caregiving (5 items), and course of the disease ( 4 items). Participants' response to risk factor items showed very poor knowledge (Table 3), where the percentage of right answers in all its items (mental exercise can prevent a person from getting $\mathrm{AD}, 3.5 \%$ ). People in their 30s may have AD (19.5\%), Hypercholesterolemia may increase a person's risk of developing AD (14.9\%), prescription drugs that delay the progression of $\mathrm{AD}$ are available (23.5\%), hypertension may increase a person's risk of developing AD (15.7\%), and genes can partially account for the development of AD (38\%). For life impact, almost $50 \%$ of the respondents correctly answered its items, where $44.4 \%$ of them reported that AD patients are prone to depression, and $49.9 \%$ safe for people with Alzheimer's disease to frequently drive car. For AD diagnosis questions, the high correct answer came from that $71 \%$ believed that $\mathrm{AD}$ is one type of dementia. For course of the disease questions, $80.2 \%$ correctly believed that a person with Alzheimer's disease needs 24-h supervision. Seventy-five percent did not have any knowledge about the average life expectancy of AD. For caregiving

Table 2 Awareness of Alzheimer's disease

\begin{tabular}{|c|c|c|}
\hline & Agree & Disagree \\
\hline $\begin{array}{l}\text { Do you think that the loss of memory and forgetting names, appointments, and task repetition of questions are } \\
\text { normal in the elderly and do not require medical consultation? }\end{array}$ & $59.8 \%$ & $40.2 \%$ \\
\hline $\begin{array}{l}\text { Do you think that the change in the planning matters of everyday life and the difficulty of balancing the financial } \\
\text { accounts is expected in the elderly? }\end{array}$ & $67.7 \%$ & $32.3 \%$ \\
\hline If one of your relatives was diagnosed with Alzheimer's disease, do you prefer not to tell the person with illness? & $56.9 \%$ & $43.1 \%$ \\
\hline $\begin{array}{l}\text { In the case of the patient diagnosed with Alzheimer's, do you think that it is best to avoid going to social events } \\
\text { and life activities in order to avoid embarrassment to the patient? }\end{array}$ & $24.4 \%$ & $75.6 \%$ \\
\hline Alzheimer's disease may result from black magic or psychological distressor bad eye? & $34.9 \%$ & $65.1 \%$ \\
\hline $\begin{array}{l}\text { In the case of the appearance of symptoms of dementia and memory disorder for a relative, will you resort to the } \\
\text { popular types of alternative medicine? }\end{array}$ & $14.2 \%$ & $85.8 \%$ \\
\hline $\begin{array}{l}\text { In case of difficulty in performing everyday tasks in a patient with Alzheimer's, do you see it necessary to resort to } \\
\text { the judiciary to save the patient's rights? }\end{array}$ & $73.7 \%$ & $26.3 \%$ \\
\hline Do you feel embarrassed if the diagnosis of your relative is Alzheimer's disease? & $7.1 \%$ & $92.9 \%$ \\
\hline Do you tend to deny the diagnosis when one of your relatives has Alzheimer's disease? & $9.8 \%$ & $90.2 \%$ \\
\hline Are you with the care of these patients in nursing homes by the state instead of keeping them at home? & $13.9 \%$ & $86.1 \%$ \\
\hline
\end{tabular}


Table 3 Knowledge of Alzheimer's disease

\begin{tabular}{|c|c|c|c|}
\hline & \multicolumn{3}{|l|}{ Answer } \\
\hline & Wrong & Right & $\begin{array}{l}\text { Do not } \\
\text { know }\end{array}$ \\
\hline \multicolumn{4}{|l|}{ Risk factors } \\
\hline It has been scientifically proven that mental exercise can prevent a person from getting Alzheimer's disease. & $64.5 \%$ & $3.5 \%$ & $32 \%$ \\
\hline People in their 30s can have Alzheimer's disease. & $28.3 \%$ & $19.5 \%$ & $52.2 \%$ \\
\hline Having high cholesterol may increase a person's risk of developing Alzheimer's disease. & $10 \%$ & $14.9 \%$ & $75 \%$ \\
\hline Prescription drugs that help delay progression of Alzheimer's disease are available. & $17.2 \%$ & $23.5 \%$ & $59.2 \%$ \\
\hline Having high blood pressure may increase a person's risk of developing Alzheimer's disease. & $13.5 \%$ & $15.7 \%$ & $70.7 \%$ \\
\hline Genes can only partially account for the development of Alzheimer's disease. & $14.5 \%$ & $38 \%$ & $47.5 \%$ \\
\hline \multicolumn{4}{|l|}{ Life impact } \\
\hline People with Alzheimer's disease are particularly prone to depression. & $7.4 \%$ & $44.4 \%$ & $48.3 \%$ \\
\hline Most people with Alzheimer's disease live in nursing homes. & $12.7 \%$ & $46.5 \%$ & $4.8 \%$ \\
\hline It is safe for people with Alzheimer's disease to drive, as long as they have a companion in the car at all times. & $27.7 \%$ & $49.9 \%$ & $22.3 \%$ \\
\hline \multicolumn{4}{|l|}{ Assessment and diagnosis } \\
\hline $\begin{array}{l}\text { When a person with Alzheimer's disease becomes agitated, a medical assessment might reveal other health problems } \\
\text { that caused the agitation. }\end{array}$ & $3.4 \%$ & $41 \%$ & 55.6 \\
\hline If trouble with memory and confusion started suddenly, it is likely due to Alzheimer's disease. & $20.2 \%$ & $37 \%$ & $42.9 \%$ \\
\hline Symptoms of severe depression can be mistaken for symptoms of Alzheimer's disease. & $17.8 \%$ & $25.4 \%$ & $56.8 \%$ \\
\hline Alzheimer's disease is one type of dementia. & $9.4 \%$ & $71 \%$ & $19.7 \%$ \\
\hline \multicolumn{4}{|l|}{ Course } \\
\hline After symptoms of Alzheimer's disease appear, the average life expectancy is 6 to 12 years. & $10.7 \%$ & $14.3 \%$ & $75 \%$ \\
\hline In rare cases, people have recovered from Alzheimer's disease. & $24.7 \%$ & $16.6 \%$ & $58.7 \%$ \\
\hline A person with Alzheimer's disease becomes increasingly likely to fall down as the disease gets worse. & $5.9 \%$ & $55.4 \%$ & $38.7 \%$ \\
\hline Eventually, a person with Alzheimer's disease will need 24-h supervision. & $4.7 \%$ & $80.2 \%$ & $15.1 \%$ \\
\hline \multicolumn{4}{|l|}{ Caregiving } \\
\hline People with Alzheimer's disease do best with simple instructions given one step at a time. & $10.4 \%$ & $40.2 \%$ & $49.4 \%$ \\
\hline $\begin{array}{l}\text { When people with Alzheimer's disease begin to have difficulty taking care of themselves, caregivers } \\
\text { should take over right away. }\end{array}$ & $86.5 \%$ & $5.3 \%$ & $8.2 \%$ \\
\hline $\begin{array}{l}\text { If a person with Alzheimer's disease becomes alert and agitated at night, a good strategy is to try to } \\
\text { make sure that the person gets plenty of physical activity during the day. }\end{array}$ & $12.3 \%$ & $42.8 \%$ & $44.9 \%$ \\
\hline $\begin{array}{l}\text { When people with Alzheimer's disease repeat the same question or story several times, it is helpful } \\
\text { to remind them that they are repeating themselves. }\end{array}$ & $25 \%$ & $49 \%$ & $26.1 \%$ \\
\hline Once people have Alzheimer's disease, they are no longer capable of making informed decisions about their own care. & $68.3 \%$ & $5.4 \%$ & $26.3 \%$ \\
\hline \multicolumn{4}{|l|}{ Treatment } \\
\hline People whose Alzheimer's disease is not yet severe can benefit from psychotherapy for depression and anxiety. & $4.4 \%$ & $47.9 \%$ & $47.7 \%$ \\
\hline Poor nutrition can make the symptoms of Alzheimer's disease worse. & $6.6 \%$ & $63.6 \%$ & $29.8 \%$ \\
\hline When a person has Alzheimer's disease, using reminder notes can contribute to decline. & $12.5 \%$ & $43.7 \%$ & $43.7 \%$ \\
\hline Alzheimer's disease cannot be cured. & $27.6 \%$ & $27.5 \%$ & $44.9 \%$ \\
\hline \multicolumn{4}{|l|}{ Symptoms } \\
\hline Tremor or shaking of the hands or arms is a common symptom in people with Alzheimer's disease. & $20.9 \%$ & $25.9 \%$ & $53.2 \%$ \\
\hline Trouble handling money or paying bills is a common early symptom of Alzheimer's disease. & $17.7 \%$ & $33.3 \%$ & $49.1 \%$ \\
\hline One symptom that can occur with Alzheimer's disease is believing that other people are stealing one's things. & $10.6 \%$ & $41.6 \%$ & $47.8 \%$ \\
\hline Most people with Alzheimer's disease remember recent events better than things that happened in the past. & $16.5 \%$ & $50.7 \%$ & $32.8 \%$ \\
\hline
\end{tabular}


domain, people with Alzheimer's disease begin to have difficulty taking care of themselves; caregivers should take over right away (5.3\% correct answer) and they are no longer capable of making informed decisions about their own care $(5.4 \%$ correct answer). For symptoms, $63.6 \%$ of the respondents correctly believed that poor nutrition can make the symptoms of AD worse. Almost $50.7 \%$ of people with $\mathrm{AD}$ can remember recent events better than things that happened in the past. Only $25.9 \%$ of the participants correctly believed that tremor or shaking of the hands or arms are common symptoms in people with AD.

Participants had the overall mean score of knowledge 10.74 out of 30 (35.8\% correct) on the $\mathrm{AD}$ knowledge scale items (Fig. 1). Participants were most knowledgeable about the treatment domain (17\%), followed by the course (16\%), assessment and diagnosis (16\%), symptoms (14\%), caregiving, and life impact (13\%). They were least knowledgeable about risk factors (11\%).

More than one thousand participants (75\%) preferred getting information about $\mathrm{AD}$ from relatives or friends, while $32 \%$ suggested getting the information from social media and websites, and $28 \%$ take the information from the medical websites.

Data comparative analysis (Table 4) has demonstrated that persons who knew someone with $\mathrm{AD}(12.76 \pm 4.71)$ had more knowledge about AD than those did not $(10.13 \pm 5.08)(t$ tests, $P<0.05)$. Also, $t$ test suggested that females $(11.04 \pm 4.2)$ had more knowledge than males $(10.35 \pm 5.55)(P<.05)$. There was a significant difference of $\mathrm{AD}$ knowledge between different age groups (using ANOVA test, $P<0.05$ ), while education levels did not show significant difference.

\section{Discussion}

There is a lack of published literature assessing the Knowledge of Alzheimer's disease, especially in Aseer region and in Saudi Arabia generally. The present study
Table 4 Mean score knowledge by characteristic variables

\begin{tabular}{llll}
\hline Variables & & Mean \pm SD & $P$ value \\
\hline Age (years) & $<30$ & $11.26 \pm 5.01$ & $0.003^{* *}$ \\
& $30-60$ & $10.36 \pm 5.16$ & \\
Gender & $>60$ & $9.70 \pm 5.43$ & \\
Family history & Male & $10.35 \pm 5.55$ & $0.014^{*}$ \\
& Female & $11.04 \pm 4.2$ & \\
Education level & No & $10.13 \pm 5.08$ & $0.000^{*}$ \\
& Yes & $12.76 \pm 4.71$ & \\
& Elementary & $10.46 \pm 4.19$ & \\
& Intermediate & $10.25 \pm 4.96$ & \\
& Secondary & $10.47 \pm 4.74$ & \\
& Bachelor & $10.87 \pm 5.19$ & \\
& Post-bachelor & $10.48 \pm 5.72$ & \\
\hline
\end{tabular}

* Significant difference using $t$ test

**Significant difference sunning ANOVA test

was designated to investigate the knowledge and awareness of Aseer region residents toward Alzheimer's disease. The obtained results revealed a modest overall knowledge scores for participants, where only $18.9 \%$ answered more than 15 questions correctly (out of 30) indicating the insufficient knowledge regarding Alzheimer's disease. Consistent with our previous findings [16], knowledge about risk factors to develop Alzheimer (for example hypertension, high cholesterol level) was only recognized by a smaller percentage of participants $(15.7 \%, 14.9 \%)$ respectively. Adequate public awareness, knowledge, and good understanding of the risk factors of Alzheimer's disease are considered to be essential for care of patients [17]. In our study, $49.9 \%$ of the respondents had great or fair knowledge of Alzheimer's disease. Previous data demonstrated that public knowledge about genetic predisposition was reasonable, yet their knowledge about modifiable risk factors for dementia was limited [18]. Hicks and Miller [19] reported that about one

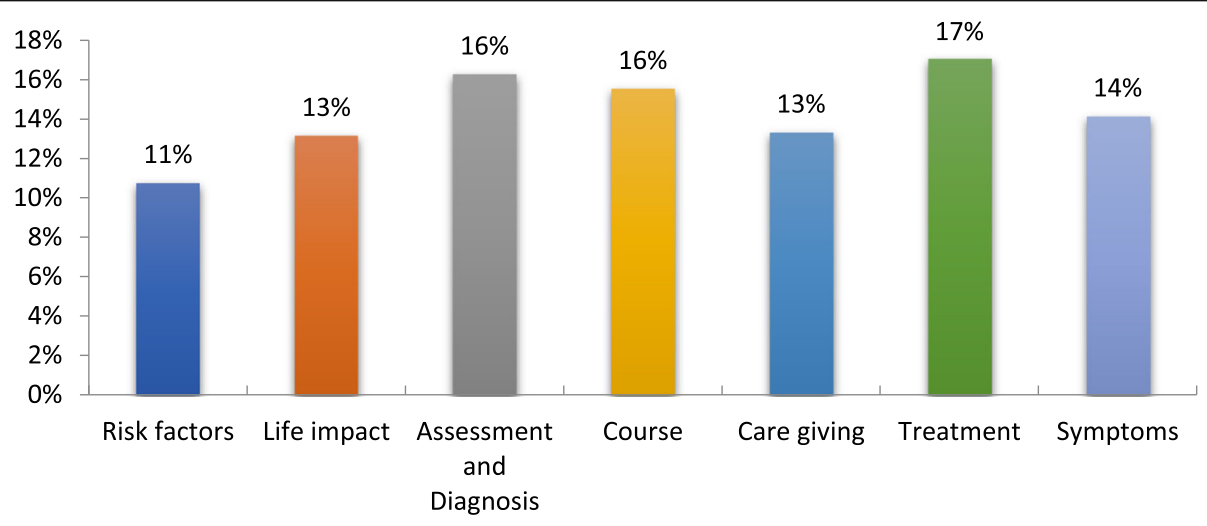

Fig. 1 Domain specific knowledge of Alzheimer disease 
quarter of the respondents were aware that hypertension and high cholesterol increase the individual's risk of developing dementia. In another study, over onethird (39\%) of the respondents identified smoking as a risk factor [20]. In contrast, knowledge of age as a risk factor for dementia seems good in most studies reviewed. In another report, 17 studies have been reviewed, were it was found that participants had only a fair to moderate level of knowledge about AD and dementia in the majority of these studies, while awareness of AD symptoms was good as well as the knowledge of risk factors and other aspects of the disease [18].

In the present study, the overall mean score of knowledge was 10.74 out of 30 (only $35.8 \%$ were answered correctly) suggesting that the participants had insufficient knowledge regarding AD. Knowledge was inadequate in some domains of the ADKS such as their knowledge about the treatment (17\%), followed by the course (16\%), assessment and diagnoses (16\%), symptoms (14\%), caregiving, and life impact (13\%). They were less knowledgeable about risk factors (11\%) and this number was significantly lower than the sample of Norwegian clinical psychologists (24.01) [20]. More women than men have Alzheimer's disease, where almost twothirds (3.2 million) of American with Alzheimer's are women [5]. This ratio was explained by women's longer lifespan; they are more likely to reach an age of high risk for Alzheimer's. Moreover, aged men however may have a higher death rate from cardiovascular disease than women in that age. There is no evidence that women are more likely than men to develop dementia at any given age [21]. The mean knowledge score for females was slightly higher than males. In a similar manner, persons who knew someone with AD had more positive attitudes than those with no experience with the disease. Also, the participant ages have negative attitudes toward mean knowledge of AD. These findings could be due to better exposure to the people with $\mathrm{AD}$.

\section{Conclusion}

Because of the increasing prevalence of dementia in general and $\mathrm{AD}$ in particular, and the high associated burden of disease, morbidity, and disability, there is an urgent need to raise the public awareness about $\mathrm{AD}$ in parallel to clinical studies aiming to improve diagnosis and treatment modalities. This work represents the first of its kind that examines $\mathrm{AD}$ knowledge in a relatively large sample of exclusive Aseer region people. The gaps in knowledge that were observed in our study require more attention to raise the awareness about Alzheimer's disease and dementia overall. These results confirm the importance of local media to disseminate the basic knowledge about AD to the Saudi citizens. Moreover, the way through which $\mathrm{AD}$ is explained through media should accommodate the needs of people at different education levels and different ages. Our results also suggest the need to extend the ongoing $\mathrm{AD}$ education programs to identify risk individuals and their families and to improve the quality $\mathrm{AD}$ care.

\section{Abbreviations \\ AD: Alzheimer's disease; ADKS: Alzheimer's disease Knowledge Scale}

\section{Acknowledgements}

Not applicable

\section{Authors' contributions}

AA (methodology, data collection, analysis, writing, and reviewing the manuscript ), AM (methodology, data collection, analysis, and writing the manuscript), MA (methodology, data collection, analysis, and writing the manuscript), TA (methodology, data collection, analysis, and writing the manuscript), AZ (methodology, data collection, analysis ), The author(s) read and approved the final manuscript.

\section{Funding}

Not applicable

\section{Availability of data and materials}

Not applicable (the data can be given upon request)

\section{Ethics approval and consent to participate}

The ethical approval for conducting this study was obtained from Head of Research Ethics Committee in King Khalid University (REC) \# 2016-08-23. The informed consent of participants was obtained prior to their participation in this study.

Consent for publication

Not applicable

\section{Competing interests}

The authors declare that they have no competing interest.

\section{Author details}

${ }^{1}$ Department of Medicine, Neurology Unit, College of Medicine, King Saud University, Riyadh, Saudi Arabia. ${ }^{2}$ Department of Medicine, King Fahad Medical City, Riyadh, Saudi Arabia. ${ }^{3}$ King Fahad Hospital-Jeddah, Jeddah, Saudi Arabia. ${ }^{4}$ Armed Forces Hospitals Southern Region, Khamis Mushait, Saudi Arabia. ${ }^{5}$ Abha Mental Health and Psychiatry Hospital, Abha, Aseer Region, Saudi Arabia.

Received: 13 March 2020 Accepted: 8 July 2020

Published online: 23 July 2020

References

1. Brookmeyer R, Johnson E, Ziegler-Graham K, Arrighi HM. Forecasting the global burden of Alzheimer's disease. Alzheimers Dement. 2007;3(3):186-91.

2. Ogunniyi A, Daif AK, Al-Rajeh S, Abdul Jabbar M, Al-Tahan AR, et al. Dementia in Saudi Arabia: experience from a university hospital. ActaNeurol Scand. 1998;98(2):116-20.

3. Pedersen NL. Reaching the limits of genome-wide significance in Alzheimer disease: back to the environment. JAMA. 2010;303(18):1864-5.

4. Terry RD, Katzman R. Senile dementia of the Alzheimer type. Ann Neurol. 1983;14:497-506.

5. Hebert LE, Weuve J, Scherr PA, Evans DA. Alzheimer disease in the United States (2010-2050) estimated using the 2010 Census. Neurology. 2013; 80(19):1778-83.

6. Williams O, Keady J, Nolan M. Younger-onset Alzheimer's disease: learning from the experience of one spouse carer. J Clin Nurs. 1995;4(1):31-6.

7. Saudi Arabia demographics profile 2016: Index mundi.

8. Ministry of health in Saudi Arabia statistics, world Álzhimers day 2013.

9. Hebert LE, Scherr PA, Bienias JL, Bennett DA, Evans DA. Alzheimer disease in the US population: prevalence estimates using the 2000 census. Arch Neurol. 2003;60:1119-22. 
10. Clare L, Marková IS, Roth I, Morris RG. Awareness in Alzheimer's disease and associated dementias: theoretical framework and clinical implications. AgingMent Health. 2011;15(8):936-44.

11. Yang HF, Cong JY, Zang XY, Jiang N, Zhao Y. A study on knowledge, attitudes and health behaviours regarding Alzheimer's disease among community residents in Tianjin, China. J PsychiatrMent Health Nurs. 2015; 22(9):706-14.

12. Smith BJ, Ali S, Quach H. Public knowledge and beliefs about dementia risk reduction: a national survey of Australians. BMC Public Health. 2014;14:661.

13. Connelln CM, Scott RJ, McLaughlin SJ. Public opinion about Alzheimer disease among Blacks, Hispanics, and Whites: results from a national survey. Alzheimer Dis Assoc Disord. 2007;21(3):232-40

14. Alqahtani A, Alqahtani M, Zarbah A, ALAhmari T, Alhazzani A. Public awareness, knowledge and attitude toward Alzheimer's disease in Aseer region, Saudi Arabia - community based cross sectional study (P3.096). Neurology. 2017:88(16 Suppl):P3.096.

15. General Authority of Statistics, KSA, 2010 Available from: https://www.stats. gov.sa/sites/default/files/en-assir-pulation-by-gender-govnernoratenationality_2.pdf.

16. Al Enazi ARK, Fayad EMA-E. Alzheimer's disease from the perspectives of Saudi elderly people. Middle-East J Sci Res. 2015;23(8):1787-96.

17. Casado BL, Hong M, Lee SE. Attitudes toward Alzheimer's care-seeking among Korean Americans: effects of knowledge, stigma, and subjective norm. Gerontologist. 2018;58:e25-34.

18. Carpenter BD, Balsis S, Otilingam PG, Hanson PK, Gatz M. The Alzheimer's Disease Knowledge Scale: development and psychometric properties. Gerontologist. 2009;49(2):236-47.

19. Hicks B, Miller BK. Correlates of knowledge of Alzheimer's disease among caregivers. Am J Alzheimer's Dis Other Dementias. 1994;9:31-9.

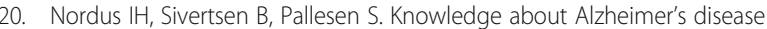
among Norwegian psychologists: The Alzheimer's disease knowledge scale. J Aging Mental Health. 2011;16(4):521-8.

21. Chene G, Beiser A, Au R, Preis SR, Wolf PA, Dufouil C, et al. Gender and incidence of dementia in the Framingham Heart. Study from mid-adult life. Alzheimers Dement. 2015;11(3):310-20.

\section{Publisher's Note}

Springer Nature remains neutral with regard to jurisdictional claims in published maps and institutional affiliations.

\section{Submit your manuscript to a SpringerOpen ${ }^{\circ}$ journal and benefit from:}

- Convenient online submission

- Rigorous peer review

- Open access: articles freely available online

- High visibility within the field

- Retaining the copyright to your article

Submit your next manuscript at $\boldsymbol{\nabla}$ springeropen.com 